\title{
Implementation of Accounting Information Systems in Large and Medium Scale Manufacturing Enterprises of Amhara Region: In Case of Selected Metropolitan Cities
}

\author{
Endalkachew Tsegaye Asmamaw \\ Department of Accounting and Finance, University of Gondar, Gondar, Ethiopia \\ Email address: \\ tsegayeendalke@gmail.com \\ To cite this article: \\ Endalkachew Tsegaye Asmamaw. Implementation of Accounting Information Systems in Large and Medium Scale Manufacturing \\ Enterprises of Amhara Region: In Case of Selected Metropolitan Cities. European Business \& Management. Vol. 7, No. 5, 2021, pp. 152-158. \\ doi: $10.11648 /$ j.ebm.20210705.12
}

Received: June 14, 2021; Accepted: July 21, 2021; Published: September 27, 2021

\begin{abstract}
Many developing countries like Ethiopia has weak accounting information system which hamper investment decisions, policy issues and contribute at large to make the entire systems in the countries inefficient. The objective of this study is examining the level of AISs implementation in large and medium scale manufacturing enterprises of Amhara region. For the purpose of this study census sampling method was employed and all large and medium scale manufacturing enterprises of Gondar and Bahirdar cities has been surveyed. Data has been collected from those enterprises through self-administered questionnaire and an in-depth unstructured interview was conducted with key informants about the subject of the study. The Collected data from the questionnaire was analyzed by using SPSS version 20 software. The regression and correlations are made to find answers for specific objectives on the basis of the result obtained from the statistical tool. Assuming the dichotomous response to the dependent variable (AISs implementation), binary logistic regression model has been used to identify the factors which influence the implementation of AISs in the study area. The finding of the study reveals that, implementation of AISs in Amhara region large and medium scale manufacturing enterprises is at its lowest level. In addition, factors such as financial capacity, organizational structure, environmental factors and relative advantage of AISs have positive and significant influence over the implementation of AISs while, complexity of AISs is found negatively influencing factor for AISs implementation. The researcher recommends that these factors should be considered by those experts of the enterprises at the time when they decide to implement AISs.
\end{abstract}

Keywords: Accounting Information Systems (AISs), Attributes of AISs, Implementation of AISs, Manufacturing, Large and Medium Enterprises, Binary Logistic Regression

\section{Introduction}

Now a day the world becomes highly globalized, due to this countries are forced to modernize and sophisticate their industries and technology in respect to world's economic trend. So, in today's global economy government actions play a critical role in shaping the competitiveness of companies that operate within their respective boundary. Government actions can have an impact on a number of competitiveness drivers including trade, financial, legal systems, infrastructure, education, science and technology [38]. The FDRE government sets a policy towards the attainment of global competitiveness by being the manufacturing hub of Africa through focus on the development of the manufacturing sector via the use of industrial parks to attract foreign direct investment and support SMEs in 2025 [12].

As in past national plans, GTP II of Ethiopia sets a growth targets underpinned by envisaged rapid structural transformation and investments in energy generation, transportation, and infrastructure to boost productivity and competitiveness [16]. For the attainment of the above country level objective, remain competitive in the world market and build an export oriented manufacturing sector, the manufacturing sector must be supported by ICT infrastructure. Taking this into consideration, large and 
medium manufacturing companies has given priority in transforming a predominantly agrarian economy to a modern and industrialized economy and alleviating poverty in the second GTP by FDRE government.

The results of Deloitte [9] study clearly show the ongoing influence of manufacturing has on driving global economies; from its influence on infrastructure development, job creation, and contribution to the gross domestic product on both an overall and per capita basis, a strong manufacturing sector creates a clear path toward economic prosperity. Failure to implement well designed AISs have adverse effects on organization success [21]. According to Nicolaou [26] AISs is a computer system that increases the control and enhances the cooperation in the organization and act as a mechanism that enables organizational strategy successful [11]. Although developing countries are eager to implement new IS technologies, the implementation of AISs in developing countries is at its lowest level in comparison with developed one. Currently it is highly reduced in many developing nations including sub-Saharan countries, but in Ethiopia it is in an infant stage of increment in AISs adoption, implementation and use [37]. As to the knowledge of the researcher, there was no any research that was conducted on the implementation of AISs in the study area even though there are some partially related studies like Wegen [37]. So, this study is designed to examine the implementation of AISs in large and medium scale manufacturing companies found in metropolitan cities of Amhara region.

\section{The Problem of the Study}

The manufacturing sector has long been considered to be the main engine of regional, national and continental economies, and thus has received the most attention from economists, management researchers, and governments [32]. Nowadays, more and more digital and on-line information is utilized in the AISs. Business organizations are needed to take an action, which put such Information Systems at the forefront, and consider both the system and the human related factors while managing their AISs [20].

Ethiopia like other developing countries has weak accounting information systems which hamper investment decisions, policy issues and leads to financial crisis and corporate failures together with their associated negative economic impacts that have been witnessed in many industrialized and developing countries [33]. The study was focused on the implementation of AISs in Ethiopia by giving particular emphasis to large and medium scale manufacturing firms found in selected metropolitan cities of Amhara region and aims to get a deeper understanding of the factors influencing the implementation of AISs by Ethiopian large and medium scale manufacturing firms. The focus of this study was to provide manufacturers, IT experts, and policymakers with the relevance of AISs that could assist in the understanding of factors that affect the implementation of AISs in Ethiopia and tries to fill the theoretical gap of implementation of AIS in manufacturing companies in
Ethiopia that was not well researched by scholars.

\subsection{General Objective of the Study}

The general objective of the study is to examine the implementation of AIS in large and medium manufacturing enterprises in case of selected metropolitan cities of Amhara region.

\subsection{Specific Objectives of the Study}

This study aimed to:

1) Examining the extent of AISs Implementation among large and medium manufacturing enterprises of Amhara national regional state.

2) Identifying driving factors that leads to AISs Implementation among large and medium manufacturing enterprises of Amhara national regional state.

3) Identifying major impeding factors for AISs Implementation among large and medium manufacturing enterprises of Amhara national regional state.

\subsection{The Significance of the Study}

In a country like Ethiopia where the contribution of manufacturing companies to the overall economic development is going to be significant, more local studies on the implementation and uses of AIS is required so as to provide the policymakers and the implementers in the area with relevant information that can help them in designing and implementing the appropriate accounting information system. Since AISs is one strategy in business, particularly for manufacturers its undeniable role must be investigated and acquainted for stakeholders. Furthermore, it may give some highlights that would serve as a basis for researchers, consultants and software developers in the area for further investigation.

\section{The Theoretical Framework and Previous Studies}

According to Alamin et al. [4] accounting information systems (AISs) defined as a software package that is installed and operated on a computer system and used to accomplish all accounting tasks, including recording, storing, retrieving, sorting, analyzing, presenting and transferring accounting information to different stakeholder groups.

Nowadays it is well acknowledged that implementation of AIS plays an indispensible role for the efficient and effective operation of businesses and sustain in the competitive environment. It increases organizational performance and helps businesses to achieve strategic objectives [24, 30, 29]; it increases the profitability and growth of business firms [2, 22]; it helps to facilitate the decision making process via providing highly qualified financial reports $[35,5]$; it helps businesses to comply with the existing tax systems of a nation [1]; it provides sustainable competitive advantage in 
the market [31]; it favors international financial reporting standards (IFRS) adoption [3]; and it helps to implement adequate internal control systems that could protect the organization's assets from fraud [34].

According to Harry et al [14] "Implementation follows the decision to adopt an innovation, and can be conceptualized as the phase where a positive decision is made operational: the decision on the part of an organization to use an ICT application is translated into a number of activities aimed at establishing the actual use of the application in the organization. Different researchers have listed many factors that have influenced IS implementation. Most of the literature regarding implementation of AISs shows that AIS implementation is influenced mainly by organizational factors like organization structure, attributes of technology, environmental factors, owner commitment, IT sophistication, IT strategy, top management support, organizational readiness, financial resources or capacity, trading partners, perceived benefit, external pressure $[5-8,15,17-19,20,21$, 23, 25, 27, 28].

What distinguished this study is that it aims at examining the extent of implementation of AISs and identifying the driving and impeding factors for AISs implementation; where no one of previous studies have discuss Ethiopian cases before.

\section{Hypothesis of the Study}

The following null hypotheses are proposed for this study:

$\mathrm{H1}$ : Organizational structure has a significant influence on the implementation of AIS in large and medium scale manufacturing firms.

H2: Financial capacity has a significant influence on the implementation of AIS in large and medium scale manufacturing firms.

H3: employees attitude towards AIS have a significant influence on the implementation of AIS in large and medium scale manufacturing firms.

H4: Environmental factors significantly influence the implementation of AIS in large and medium scale manufacturing firms.

H5: compatibility of AISs has a significant influence on the implementation of AIS in large and medium manufacturing firms.

H6: complexity of AISs has a significant influence on the implementation of AIS in large and medium manufacturing firms.

H7: relative advantage of AISs has a significant influence on the implementation of AIS in large and medium manufacturing firms.

\section{Methodology of the Study}

For achieving the objective of the study, the descriptive analytical method was used. In addition, the suitable statistical procedures, SPSS were used for testing the hypothesis and for presenting and analysis of the data.

\subsection{Method of Data Collection}

The researcher depends on two types of data during collection.

Secondary data: for developing the theoretical background of the study, the related studies of AISs about the subject of the study were received from different books, studies, reports, etc.

Primary data: the researcher made a comprehensive survey on the sample of the study by using structured questionnaire and an in-depth unstructured interview to collect data and test the hypothesis of the study. The questionnaire consisted of three parts. The first and second part aimed at collecting general data about the personal and organizational characteristics of the sample of the study. The third part aimed at getting data related to the study hypotheses.

\subsection{The Population and the Sample of the Study}

The population of the study represented all large and medium scale manufacturing enterprises of Amhara region which are 57 in number. The sample of the study takes all this enterprise managers, finance officers and IT experts and 170 questionnaires are distributed to all of them, while only 136 were retrieved successfully. The sample of the study can be described as follows.

Table 1. Description of the respondents and enterprises of the study.

\begin{tabular}{lll}
\hline Sex & N & Percentage \\
\hline Male & 101 & 74.3 \\
Female & 35 & 25.7 \\
Age & $\mathrm{N}$ & Percentage \\
18-29 & 10 & 7.4 \\
30-39 & 70 & 51.5 \\
40-49 & 48 & 35.3 \\
Above 50 & 8 & 5.9 \\
Educational status & $\mathrm{N}$ & Percentage \\
Certificate and less & 13 & 9.6 \\
Diploma & 34 & 25 \\
Degree & 75 & 55.1 \\
Masters and above & 14 & 10.3 \\
Work experience of respondents & $\mathrm{N}$ & Percentage \\
Less than a year & 3 & 2.2 \\
1-5 year & 49 & 36.0 \\
6-10 year & 62 & 45.6 \\
Above 10 year & 22 & 16.2 \\
Experience in current position & $\mathrm{N}$ & Percentage \\
Less than a year & 28 & 20.6 \\
1-5 year & 63 & 46.3 \\
6-10 year & 41 & 30.1 \\
>10 year & 4 & 2.9 \\
Category of enterprise & $\mathrm{N}$ & Percentage \\
Medium scale & 71 & 52.2 \\
Large scale & 65 & 47.8 \\
Experience in ICT (AISs) & $\mathrm{N}$ & Percentage \\
Less than a year & 19 & 14 \\
1-5 year & 85 & 62.5 \\
6-10 year & 32 & 23.5 \\
Sector of the enterprise & $\mathrm{N}$ & Percentage \\
Public sector & 24.3 \\
Private sector & 75.7 \\
\hline & \\
& 43 & \\
\hline
\end{tabular}




\section{Statistical Procedures}

The following statistical methods were used to analyze data and test the hypothesis according to SPSS version 20.0 software.

\subsection{Testing the Reliability of the Tool of the Study}

Cronbach's Alpha test was used to measure the internal reliability of the questionnaire's items and the internal consistency among the responses of the respondents which was higher than the minimum threshold of 0.7 the questionnaire used in this research is reliable.

\subsection{Testing the Multicollinearity}

To test degree of multicollinearity among explanatory variables of implementation of AISs, test of VIF can be employed after running regression. A major problem with multicollinearity is that standard errors may be inflated. Thus, if $\mathrm{VIF}>10$ or $1 / \mathrm{VIF}<0.10$ indicates trouble. A tolerance level (1/VIF) less than 0.1 and VIF greater than 10 indicates the existence of multicollinearity between the variables. So in this study there is no problem of multicollinearity between study variables since the VIF of all variables is less than 10 or $1 /$ VIF is greater than 0.10 .

\subsection{Checking Outliers}

Outliers are data points with extreme values that could have a negative effect on our estimators. To check for outliers, this study used non-graphical method of outlier's detection and found that there were no significant outliers.

\subsection{Goodness -of -fit Test of the Binary Logistic Regression Model}

Regarding goodness of fit of the overall model, this study applied omnibus test of model coefficients. An omnibus test of model coefficients is testing the null hypothesis that adding predictors to the model has not significantly increased our ability to predict the likelihood of AISs implementation. In this study the Omnibus test of model coefficients shows a Chi-Square of 127.273 which is also significant (P-value < $0.0005)$. Since the omnibus test is significant, it can be concluded that adding predictor variables to the model has significantly increased our ability to predict AISs implementation among large and medium scale manufacturing enterprise.

Table 2. Omnibus Tests of Model Coefficients.

\begin{tabular}{llllll}
\hline & & Chi-square & df & Sig. & \\
\hline \multirow{3}{*}{ Step 1 } & Step & 127.273 & 7 & .000 & .000 \\
& Block & 127.273 & 7 & .000 & 7 \\
\hline
\end{tabular}

\subsection{Model Summary}

The result of Cox and Snell R2 and Nagelkerke R2 in the above table is $0.608 \& 0.828$ respectively. However, the Nagelkerke R2 (a modification of the Cox and Snell R2) is more common and considered a better indication to observe the strength of association between the dependent and predicting variables [10]. Hence, the Nagelkerke R2 of 0.82 .8 implies that $82.8 \%$ of the variance in the dependent variable (i.e. the likelihood AISs implementation) is explained by the predictor variables included in this study.

Table 3. Model Summary.

\begin{tabular}{llll}
\hline Step & $\mathbf{- 2}$ Log likelihood & Cox \& Snell R Square & Nagelkerke R Square \\
\hline 1 & $52.672^{\mathrm{a}}$ & .608 & .828 \\
\hline
\end{tabular}

a. Estimation terminated at iteration number 8 because parameter estimates changed by less than. 001 .

\subsection{Hosmer and Lemeshow Test}

The other method of overall goodness of fit assessment of the logistic regression is Hosmer and Lemeshow test, which measures the correspondence of the actual and predicted values of the dependent variable. As can be below the significant values is greater than $0.05(0.697>0.05)$. Hair [13] argued that if the significant value in HosmerLemeshow test is greater than 0.05 , then the applied model in study is feasible for further analysis.

Table 4. Hosmer and Lemeshow Test.

\begin{tabular}{llll}
\hline Step & Chi-square & df & Sig. \\
\hline 1 & 5.552 & 8 & .697 \\
\hline
\end{tabular}




\subsection{Testing the Hypothesis}

Table 5. Variables in the Equation.

\begin{tabular}{llllllll}
\hline & & B & S. E. & Wald & df & Sig. & Exp (B) \\
\hline & ORGANIZATIONSTRUCTURE & -1.924 & .760 & 6.411 & 1 & .011 & .146 \\
& FINANCIALCAPACITY & 2.855 & .720 & 15.721 & 1 & .000 & 17.372 \\
Step 1 $^{\text {a }}$ & EMPLOYEESATTITUDE & -.346 & .785 & .194 & 1 & .659 & .707 \\
& ENVIRONMENTALFACTORS & .738 & .305 & 5.849 & 1 & .016 & 2.092 \\
& COMPATIBILITY & -.129 & .300 & .185 & 1 & .667 & .879 \\
& COMPLEXITY & -1.184 & .398 & 8.837 & 1 & .003 & .306 \\
& RELATIVEADVANTAGE & .897 & .388 & 5.339 & 1 & .021 & 2.452 \\
& Constant & -6.409 & 3.846 & 2.776 & 1 & .096 & .002 \\
\hline
\end{tabular}

a. Variable (s) entered on step 1: ORGANIZATIONSTRUCTURE, FINANCIALCAPACITY, EMPLOYEESATTITUDE, ENVIRONMENTALFACTORS, COMPATIBILITY, COMPLEXITY, and RELATIVE ADVANTAGE.

Since the econometric model (equation) in a binary logistic regression model is non-linear, only the signs of the coefficients can be directly interpreted as follows. The results presented in the table suggest that all the independent variables had significant regression coefficients apart from employee attitude and compatibility of accounting information systems.

The result of the regression shows a statistically significant positive relationship between organizational structure and implementation of AISs. Therefore, the alternative hypothesis, organizational structure has positive significant influence on the implementation of AIS is accepted. This finding is consistent with the finding of Brynjolfsson et al. [7], who concludes that in the presence of complementary organizational structure more intense implementation and use of AISs in the enterprises should avail. Similarly, [21] found that organizational structure is a contributory factor on the implementation of AISs. Enterprises extent of implementing AISs is dominantly affected by their inefficient organizational structure (both in aligning AISs and evolving a structure).

The result of binary logistic regression shows a statistically significant positive relationship between financial capacity and the implementation of accounting information system with a P-value of 0.000 . Thus, the alternative hypothesis, There is a significant positive relationship between financial capacity and implementation of AIS in large and medium scale manufacturing firms is accepted and this relationship between financial capacities and AISs implementation is similar with the findings of Juris [19] and contradicted with Mahdi Salehi et al. [21] result.

As shown from the above regression result table there exists a negative but insignificant relationship between employees attitude towards AISs and the likelihood of AISs implementation $(\beta=-0.552, \mathrm{P}$-value $>0.05)$. Therefore the hypothesis, there is significant positive relationship between employees attitude towards AISs and implementation of AISs is rejected. This implies that employees attitude towards AISs has little impact on the enterprise's decision to implement AISs. However, contrary to this finding, Juris [19] argued that employee's attitude towards AISs is a significant barrier for the implementation of AISs among large and medium scale business enterprises.
With regard to the effect of environmental factors (competitive pressure, government support, rivalry's in the industry and enterprises internal environment), the study found a positive and 54 statistically significant relationship between environmental factors and AISs implementation therefore the alternative hypothesis is accepted. This finding is consistent with the finding of Juris [19] and Mahdi Salehi et al. [21].

As revealed in the binary logistic regression result above Compatibility of AISs has a negative insignificant relationship with the implementation of AISs. This result indicates that the impact of compatibility of AISs is little in influencing the decision of manufacturing enterprises whether to implement AISs or not. However, many of researchers [36, 19, 25] argued that compatibility of AIS technologies with the current accounting practices, structure and values of business organization is a key factor that affects AISs implementation so the alternative hypothesis is rejected.

With regard to complexity of AISs, the result of binary logistic regression shows negative and significant relationship with AISs implementation with a $\mathrm{p}$ value of 0.003 . Thus, the alternative hypothesis is accepted and this relationship between AISs implementation and complexity of AIS leads to the argument that if the AISs are more complex (difficult to understand \& use, require high technical \& operating skill and need cooperation) the tendency to implement AISs should be lower. This finding is consistent with Juris [19]; Ngadiman et al. [27] and Amanamah et al. [5].

Since relative advantage of AISs and implementation of accounting information systems found to be having a positive and significant relationship in this study, the alternative hypothesis is accepted. This suggests that if the manufacturing enterprises perceive that AISs reduce poor communication, reduce costs of business process, accomplish accounting tasks accurately and quickly and enhance market opportunities, the extent of implementation of AISs should be high. The result is consistent with the findings of Tornatzky et al. [36]. Similarly, Budiarto et al. [8] has found significant relationship between relative advantage and AISs implementation. Amanamah et al. [5] also confirmed that there exist a positive and significant relationship between relative advantage and implementation of AISs. 


\section{Conclusion}

The first objective in this study was to determine the extent of AISs implementation in amhara region large and medium scale manufacturing enterprises. The result of this study shows that out of the total surveyed enterprises in selected metropolitan cities $62.5 \%$ of them do not implement accounting information systems in their business so as to modernize their systems and remain competitive in the strongly fierce business world which is abreast of quick changes and only $37.5 \%$ enterprises implement AISs so as to be sustainable and continually competitive in business. This finding implies and acknowledges that there exist low AISs implementations in amhara region large and medium scale manufacturing enterprises. Due to that the level of modernity in using current and timely information of the businesses affair via computerized accounting information systems which uses latest online real time processing and reporting method is inefficient which constitute only $19.9 \%$.

The results of the binary logistic regression shows that flexible and appropriate organizational structure, adequate financial capacity, stiff global competition and relative advantage from the use of AISs are the driving factors for the AISs implementations in amhara region large and medium scale manufacturing enterprises. The study has also examined the relationship between complexity of AISs and AISs implementation and found it the only impeding factor under this study for having good tendency of implementing accounting information systems.

\section{Recommendation}

Based on the findings of the study the following recommendations are forwarded that may help the enterprises, policy makers, practitioners of AISs, IT technical and functional experts, and managers, owners of manufacturing enterprises and those parties who have an interest on it to successfully implement AISs and obtain all required and available merits from it.

The organizational structure should be more flexible to accept changes because it enables the enterprises to acquire packages/canned/off- the- shelf/ AISs which are cheap, error free, Quick fix than in-house developed AISs which are expensive, error prone, time taking and risky.

Enterprises should have sufficient financial capacity that enables them to implement AISs in a proper manner without any great constraint in technology and trained manpower.

Enterprises should have to strive on implementing and using AISs to be competent on the global market and managers and executives of the enterprises must strive in developing new strategies that enable them to be competent. Furthermore, government body of the country should have to tire in designing appropriate policies and strategies that can be the back bone of manufacturing enterprises in enabling them the leading in efficiency and effectiveness. Here also those AISs experts who engage in developing and supplying AISs in the organizations or by their own selves have to align organizational current status and global economy by their undeniable effort of developing new high-tech AISs.

AISs shouldn't be as such complex and require high technical and operating skill that can highly eradicate enterprises and employees exposure for implementation of AISs without any threat in their enterprise. So developers of AISs have to design less complex AISs that can be aligned with organizations requirement. These kinds of characteristics of AISs are undeniable role in enhancing unstoppable technological innovations of countries.

The study finds that relative advantage of AISs have a profound effect on implementation decision of AISs among large and medium scale manufacturing enterprises of Amhara region. This finding suggests that if there is high relative advantage of AISs, the probability to implement them with in their enterprise is higher. Therefore managers and AISs practitioners are responsible in doing cost benefit analysis of the AISs to opt the cheapest and high yield AISs that can make the enterprise successful and efficient in all respects.

\section{References}

[1] Abdallah, A. A. J. (2014). The impact of using accounting information systems on the quality of financial statements submitted to the income and sales tax department In Jordan. European Scientific Journal.

[2] Ahmad, A. Y. A. B. (2013). The Ability of Accounting Information Systems to support Profitability and Growth. Industrial Sector-Jordan Companies.

[3] Akanbi, T. A., \& Aruwaji, A. M. (2016). Effect of accounting information systems in manufacturing industries in Nigera. Electronic copy available at: $\mathrm{https}: / / \mathrm{ssrn} . \mathrm{com} /$ abstract=2872047.

[4] Alamin, A., Yeoh, W., Warren, M. \& Salzman, S. (2015). An empirical study of factors influencing accounting information systems adoption among accountants. Twenty-Third European conference on Information Systems. Münster, Germany.

[5] Amanamah, R. B., Morrison, A., \& Asiedu, K. (2016). Computerized Accounting Systems Usage by Small and Medium Scale Enterprises in Kumasi Metropolis, Ghana. Research Journal of Finance and Accounting.

[6] Awosejo, P. P., Ajala, E. B., \& Agunbiade, O. Y. (2014). Adoption of Accounting Information Systems in an Organization in South Africa. African Journal of Computer \& ICT.

[7] Brynjolfsson E. \& Hitt L.(2002) "Computing productivity: Firm-level evidence", MIT Working Paper 4210-01.

[8] D. Setyo Budiarto \& M. Agung Prabowo (2015). Accounting Information Systems Alignment and SMEs Performance in Indonesia: International Journal of Management, Economics and Social Sciences.

[9] Deloitte (2016), Global manufacturing competitiveness Index.

[10] Field, A. (2009). Discovering statstics using SPSS. $3^{\text {rd }}$ edition. SAGE publications inc. Los Angeles, USA. 
[11] Gerdin, J., Greve, J. (2004). Forms of contingency fit in management accounting research-a critical review, Accounting, organizations and society.

[12] Growth and Transformation plan of Ethiopia II, (2016).

[13] Hair, J. F., Black, W. C., Babin, B. J., Anderson, R. E. and Tatham, R. L. (2010) Multivariate data analysis, Prentice Hall Upper Saddle River, NJ.

[14] Harry Bouwman, Bart van den Hooff, Lidwien van de Wijngaert, Jan van Dijk ICT and organizations, 2005.

[15] Hussin, H. King, M. \& Craig, P. (2002). IT alignment in small firm. European Journal of Information Systems.

[16] International monetary fund (2016), Report.

[17] Ismail NA, \& King, M. (2006). The alignment of accounting and information systems in SMEs in Malaysia. Journal of Global Information Technology Management.

[18] Ismail, N. A. (2009). Factors influencing accounting information systems effectiveness among manufacturing SMES: Evidence from Malaysia. The Electronic Journal on Information Systems in Developing Countries.

[19] Juris ulmanis. (2011). Information and communications technology factors for adoption and useage determinants in latvian companies, doctoral thesis.

[20] Kibret Baye Assefa (Mr.) and Dr. Yuvaraj Sambasivam (2013) Evaluating the Design of Accounting Information System and its Implementation in Ethiopian Manufacturing Industries RJSITM: Volume: 02, Number 7 (2013) ISSN 2251-1563.

[21] Mahdi Salehi and Abdoreza Abdipour (2013). Accounting information system's barriers: Case of an emerging economy African Journal of Business Management Vol. 7 (5).

[22] Muhindo, A., Mzuza, M. K., \& Zhou, A. (2014). Impact of Accounting Information Systems on Profitability of Small Scale Businesses: A Case of Kampala City in Uganda. International Journal of Academic Research in Management.

[23] Muhrtala, O., \& Ogundeji, G. M. (2013). Determinants of accounting software choice. An empirical approach. Universal Journal of Accounting and Finance.

[24] Naranjo-Gil, D. (2004). The Role of Sophisticated Accounting System in Strategy Management. The International Journal of Digital Accounting Research.

[25] Ndekwa, G. A. (2015). Determinants of adopter and nonadopter of computerized accounting information systems among small and medium enterprises in Tanzania. International Journal of Innovative Science, Engineering \& Technology.
[26] Nicolaou, A. L. (2000). A contingency Model of Perceived Effectiveness in Accounting Information Systems: Organisational Coordination and Control Effects. International Journal of Accounting Information Systems.

[27] Ngadiman, Pambudi, D., Wardani, D. K, \& Sabandi, M. (2014). Determinants of accounting information technology adoption in Syria microfinance institutions. Journal of Asian Social Science.

[28] Nyang'au, R. N., Okibo, B. W., \& Nyanga'u, A. (2015). Constraints affecting adoption of computerized accounting systems in Nyeri, Kenya. International Journal of Economics, Commerce and Management.

[29] Olamide, T. F., \& Adeyemi, J. O. (2016). An Evaluation of Accounting Information System and Performance of Small Scale Enterprises in Kwara State, Nigeria. DBA Africa Management Review.

[30] Patel, P. (2015). Effects of accounting information system on Organizational Profitability. International Journal of Research and Analytical Reviews.

[31] Porter, M. (1985). Competitive advantage: Creating and sustaining superior performance. New York: free press.

[32] Raymond, L. and Sylvestre, U. (2011), "Information Technology Adoption and Assimilation: Towards a Research Framework for Service Sector SMEs", Journal of Service Science and Management.

[33] Report on observance of standards and cods in Ethiopia, (2007). World Bank. Addis Ababa, Ethiopia.

[34] Romney and Steinbart (2015), Accounting Information Systems, $13^{\text {th }}$ edition, Pearson Education Inc.

[35] Swalhah, A. (2014). The role of Accounting Information Systems (A. I. S.) in rationalized Administrative Decisionmaking (field study) Jordanian banks. Interdisciplinary journal of contemporary research in business.

[36] Tornatzky, L. G. \& Klein, K. (1982). Innovation characteristics and innovation adoption-implementation: IEEE Transactions on Engineering Management, 29 (1), 28-43.

[37] Wegen, D. (2014). Small and micro enterprises (SMEs) in Addis Ababa, Ethiopia: Development and poverty reduction through information and telecommunication technologies, with particular to hotel industry. Dissertation paper submitted to the University of West London. UK.

[38] World economic forum report, (2013). 